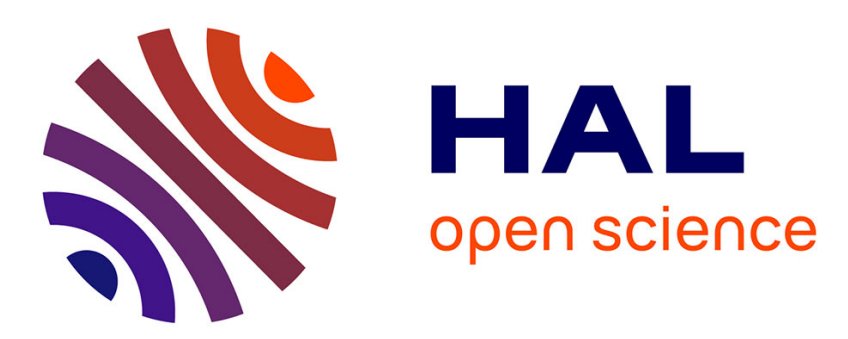

\title{
The measurement of social disadvantage and its spatial articulation in the Republic of Ireland
}

\author{
Jonathan Pratschke, Trutz Haase
}

\section{To cite this version:}

Jonathan Pratschke, Trutz Haase. The measurement of social disadvantage and its spatial articulation in the Republic of Ireland. Regional Studies, 2007, 41 (06), pp.719-734. 10.1080/00343400601120197 . hal-00514635

\section{HAL Id: hal-00514635 \\ https://hal.science/hal-00514635}

Submitted on 3 Sep 2010

HAL is a multi-disciplinary open access archive for the deposit and dissemination of scientific research documents, whether they are published or not. The documents may come from teaching and research institutions in France or abroad, or from public or private research centers.
L'archive ouverte pluridisciplinaire HAL, est destinée au dépôt et à la diffusion de documents scientifiques de niveau recherche, publiés ou non, émanant des établissements d'enseignement et de recherche français ou étrangers, des laboratoires publics ou privés. 


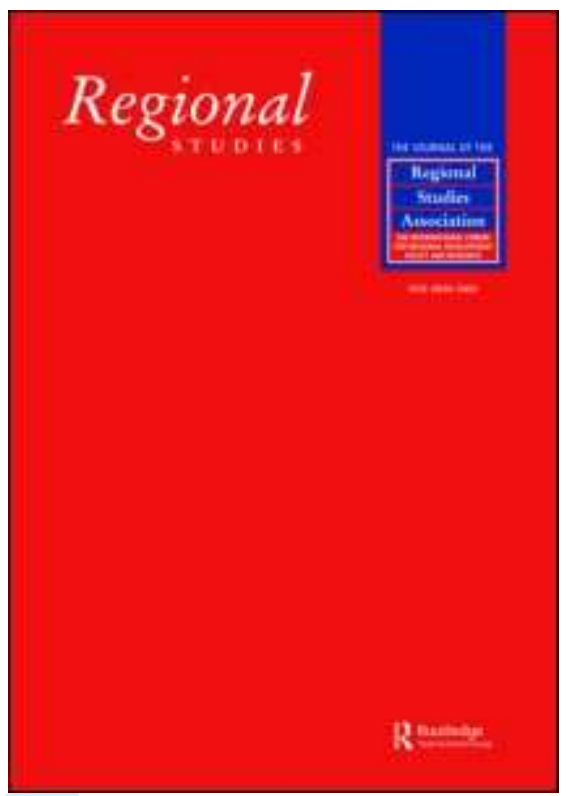

The measurement of social disadvantage and its spatial articulation in the Republic of Ireland

\begin{tabular}{|c|l|}
\hline Journal: & Regional Studies \\
\hline Manuscript ID: & CRES-2004-0006.R2 \\
\hline Manuscript Type: & Main Section \\
\hline JEL codes: & $\begin{array}{l}\text { C33 - Models with Panel Data < C3 - Econometric Methods: } \\
\text { Multiple/Simultaneous Equation Models < C - Mathematical and } \\
\text { Quantitative Methods, I32 - Measurement and Analysis of Poverty }< \\
\text { Government Policy|Provision and Effects of Welfare Programs }<\text { I3 - } \\
\text { Welfare and Poverty < I - Health, Education, and Welfare, R23 - } \\
\text { Regional Migration|Regional Labor Markets|Population < R2 - } \\
\text { Household Analysis < R - Urban, Rural, and Regional Economics }\end{array}$ \\
\hline \hline Keywords: & \begin{tabular}{l} 
Ireland, SEM, census, deprivation, disadvantage, index \\
\hline
\end{tabular} \\
\hline
\end{tabular}

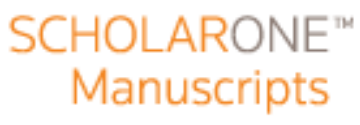




\title{
THE MEASUREMENT OF
}

\author{
SOCIAL DiSADVANTAGE
}

AND ITS SPATIAL ARTICULATION

IN THE REPUBLIC OF IRELAND

\author{
Jonathan Pratschke \\ Dipartimento di Sociologia e Scienza della Politica, \\ Università degli Studi di Salerno, \\ Via ponte don Melillo, \\ Fisciano 84084 (SA), \\ Italy. \\ email: jpratschke@unisa.it \\ \& \\ Trutz Haase \\ Social \& Economic Consultant \\ 17 Templeogue Road, \\ Terenure, \\ Dublin 7W, \\ Ireland. \\ email: thaase@iol.ie
}


'The Measurement of Social Disadvantage'

\begin{abstract}
This article contributes to policy research by developing a reliable aggregate measure of social need in small areas and by describing how this index can be used to evaluate public interventions in disadvantaged areas. Spatially-targeted initiatives to combat disadvantage have been implemented in many OECD countries, and the availability of EU funding has encouraged their diffusion. The longitudinal analysis and evaluation of these initiatives is difficult using existing indices, as these do not facilitate comparisons over time. In this article, we describe an alternative approach that relies on Confirmatory Factor Analysis and permits diachronic analyses.
\end{abstract}


Word count abstract: 100 approx.

10

JEL codes:

I32 - Measurement and Analysis of Poverty

I38 - Government Policy I Provision and Effects of Welfare

Programs

C33 - Models with Panel Data

R23 - Regional Migration I Regional Labor Markets I

Population 


\section{Introduction}

One of the aims of the European Union is to achieve greater social and economic cohesion between member states, and the EU has also committed considerable resources in recent years to the achievement of greater regional cohesion within member states. The initial development of disadvantage indices in Europe and elsewhere coincided with a growing awareness that single indicator variables can provide only a partial picture of social disadvantage within the context of spatially-targeted interventions. Over the past two decades, a number of multivariate indices have been developed with the aim of identifying localities where social need is particularly accentuated ${ }^{1}$.

Multi-faceted local development initiatives became prominent during the 1960 s as a response to concerns about the spatial concentration of poverty in inner-city areas of the US and the UK. They were first introduced to Ireland by the European anti-poverty programmes of the 1970 s and gathered momentum as a result of the establishment of twelve pilot 'Area Partnerships' under the Programme for Economic and Social Progress in 1991 and the nation-wide expansion of the Partnership idea under the Global Grant 1992-1995.

As an increasing quantity of longitudinal data on local areas has become available, researchers and policy-makers have come to realise that the methodology underlying most existing indices precludes analysis of one of the most fundamental questions relating to the spatial distribution of social disadvantage, namely how this evolves over time. Most existing indices of social disadvantage provide a static, cross-sectional view 
of disadvantage, producing scores that cannot be compared directly over time. The aim of this article is to present a theoretically-grounded, robust and innovative approach to the measurement of disadvantage that can overcome this obstacle and, as a result, provide a tool for evaluating area-based initiatives.

\section{Conceptualising Social Disadvantage}

The most widely-used definitions of disadvantage found in the social science literature emphasise differential access to resources, following Townsend's seminal work in Poverty in the United Kingdom: "Individuals, families and groups can be said to be in poverty if they lack the resources to obtain the types of diet, participate in the activities and have the living conditions and amenities which are customary, or at least widely encouraged or approved in the societies to which they belong" (1979: 31). Townsend's definition remains extremely influential and has been incorporated into successive British government reports and independent research. Noble et al. (1999), for example, suggest that deprivation "refers to unmet need, which is caused by a lack of resources of all kinds, not just financial" (p. 7).

In this article we will seek to extend this approach by adopting a broad definition of resource exclusion and by shifting our theoretical focus from the individual to the aggregate level. Whereas Townsend and other researchers have tended to conceptualise disadvantage as an individual attribute, we emphasise social resources such as labour market opportunities and demographic vitality as well as the impact of broader social 
structures and processes such as social stratification: "From a structural perspective individual characteristics such as education and income are determined by broader social factors that in turn provide the primary route for social policy interventions. ... Area-based measures of deprivation, although mainly aggregates of individual characteristics, move towards reflecting structural elements related to area and community..." (Salmond and Crampton, 2002: 14-15).

A number of consequences follow from this: firstly, the most deprived areas are not always those with the highest percentages of deprived individuals. Secondly, key concepts in individual-level analysis such as "multiple deprivation" and "at-risk groups" become increasingly problematic as we move to the aggregate level. This is because the coincidence within a given area of high levels of unemployment and poor health, for example, does not imply that the same individuals are affected by both unemployment and poor health.

The meaning of certain indicators can also undergo transformation as we shift from the individual to the aggregate level. At the individual level, being 25 to 44 years of age does not even denote membership of a population that could be considered "at risk of deprivation". However, at the aggregate level, the relative size of this age cohort is a powerful indicator of a real, demonstrable form of social disadvantage, characterised by

sustained emigration and the "demographic decline" that this provokes. Taylor (1998) sustains that the construction of deprivation indices should be guided by the policy goals which they are intended to serve. As far as the present index is concerned, the main aim is to provide the Irish Government (which has supported the 
1

4

5

6

7

8

9

10

11

12

13

14

15

16

17

18

19

20

21

22

23

24

25

26

27

28

29

30

31

32

33

34

35

36

37

38

39

40

41

42

43

44

45

46

47

48

49

50

51

52

53

54

55

56

57

58

59

60

research over a number of years and adopted the resulting measure as the official areabased index of affluence and disadvantage) with a means (a) to identify significant clusters of disadvantage in order to establish area-based initiatives; (b) to construct resource allocation models that take disadvantage into account; (c) to provide community groups and local service providers with an overview of the spatial articulation of affluence and disadvantage within their catchment areas; (d) to monitor and evaluate area-based interventions; (e) to explore the influence of social disadvantage in epidemiological, educational, economic and political research. 
One of the most important characteristics of disadvantage, when conceptualised as a collective, social phenomenon, is its multidimensional nature. Before discussing the nature of the specific dimensions of disadvantage in Ireland, however, it is important to clarify what we mean by the term "dimension". A number of researchers use the terms "dimension" and "domain" interchangeably to refer to thematic areas such as education or income. In measurement theory, however, a set of indicators form part of a single dimension if their values vary together systematically, and this holds regardless of whether they belong to different thematic domains. For example, educational attainments are strongly associated with occupation and income, and these variables are often viewed as forming a single dimension of variation due to their close causal links

All disadvantage indicators are inter-related in this way and lie along a stable number of dimensions. Whilst thematic domains can represent a useful heuristic tool when surveying the available data sources, analysis of dimensional structure should arguably take precedence during the final stages of index construction. These considerations are of relevance, for example, to the indices developed by Michael Noble and his team at the University of Oxford (Noble et al., 2000a, 2000b, 2001, 2003). Their Index of Multiple Deprivation 2000 comprises six ward-level domains: Income, Employment, Health Deprivation and Disability, Education, Skills and Training, Housing and Geographical Access to Services. When these domains are weighted and summed, the dimensions that most strongly characterise them are also implicitly assigned a weighting. In this case, a mainly “urban”, labour market-based dimension predominates,
Deleted: : "[t]hose facing the broadest range of choices (the more money you have or are able to borrow the greater your choice in the housing market) tend to be those who have already enjoyed choices and opportunities earlier in life (which university to attend, which career to follow). Advantages also accumulate inter-generationally. Those who inherit money from parents or grandparents are more likely to be able to use that to pay for housing or perhaps to improve the condition of their home" (Shaw et al., 2001: 299). 
given the absence of measures more fully reflecting social class composition and "rural" forms of disadvantage, and given the low weighting assigned to the domain measuring access to services $^{2}$. In Ireland and in most countries of the Southern and Eastern European periphery, the failure to address rural disadvantage leads to an underestimation of the problems faced by disadvantaged areas where long-standing Deleted: this approach would underplay adverse labour market conditions have given rise to sustained emigration.

We are now in a position to return to the question of how the underlying dimensions of disadvantage should be theorised. A detailed literature review and exploratory statistical analyses have led us to identify three dimensions of social disadvantage: demographic decline, social class disadvantage and labour market deprivation (Haase, 1999; Pratschke, 2002). The first of these - 'demographic decline' - is based on the insight that emigration has influenced Ireland's demographic experience for more than a century, with the result that the unemployment rate tends to understate the extent of labour market disadvantage in certain areas, as this is partly concealed by underemployment or withdrawal from the labour market (Haase, 1999).

Unemployment, and particularly long-term unemployment, nevertheless remain important causes of disadvantage and are responsible for the most concentrated forms of disadvantage found in urban areas. In areas with particularly high unemployment rates, young people face considerable difficulties in obtaining educational credentials and are handicapped by 'labelling effects', by the lack of role models and by initial difficulties in entering the labour market. As Wilson (1987) has argued in relation to the US, the social isolation and disorganisation which characterises areas of concentrated unemployment itself represents an obstacle to the labour force participation of young 
'The Measurement of Social Disadvantage'

people. Furstenberg and Hughes (1997) report that in US neighbourhoods characterised by high unemployment rates, families often experience a breakdown of social ties and a loss of community consensus, leading to a decline in participation in community institutions and informal networks.

The third determinant of the well-being of communities is their social class composition: areas with a weak social class profile are more vulnerable to the effects of economic restructuring and recession and are more likely to experience low pay, dangerous working conditions and poor housing. By virtue of its relational nature, social class should be treated as a social relationship defined by the level of control exercised by social groups over productive resources (Shaw et al., 2001; Wright, 1985). Not only is low-skilled work associated with low wage levels and poor working conditions, communities in which a large proportion of the workforce are engaged in low-skilled jobs or small farming have profound structural weaknesses.

\section{Indicator Selection}

Most existing disadvantage indices rely on data from the Census of Population, although recent developments in Britain have established an important precedent in relation to the use of non-Census data (see, for example, Noble et al., 2000b). This is superficially rather attractive, as data on benefits take-up, for example, are strongly linked with disadvantage and are available on a more timely basis than the Census.

However, the use of such data creates a number of rather intractable problems: where 
legislative measures, administrative practices and technical procedures change, administrative data can undergo transformation, rendering comparisons difficult across time and between jurisdictions. It is striking, for example, that the recent UK Indices of Multiple Deprivation preclude the comparative analysis of English, Scottish and Welsh deprivation scores along the borders. Moreover, historical data relating even to the recent past are generally not available, rendering retrospective analysis impossible. Nevertheless, where stable administrative data are available at a high level of spatial disaggregation, their inclusion within deprivation indices may be warranted, although this is not yet possible within the Irish context.

As far as the timeliness of Census data is concerned, we have found area-level disadvantage scores to be highly stable over time, implying that we do not need to constantly update our analyses (cf. Dorling et al., 2000; Gregory et al., 2000; SEU, 1998). Although the raw values of the individual indicators may vary over time (particularly those relating to the labour market), the relative values of the aggregate index scores tend to be much more stable, as we will show later in this article. This relative invariance is in line with the existing literature on area-level deprivation, which emphasises the difficulties involved in reversing the fortunes of disadvantaged areas (Lupton, 2003).

Having outlined the three main dimensions of social disadvantage for the Republic of ${ }^{+}$ Ireland, we will now provide a brief summary of the indicator variables that we have selected to measure these. We will use the age dependency rate ${ }^{3}$ and the decline in population ${ }^{4}$ over the previous five years as the first two indicators of Demographic Decline. The core working-age population has the highest rate of geographical mobility,
Deleted: as

Deleted: the resulting

Deleted: constant

Deleted: extremely 
which means that areas of decline typically have disproportionate shares of young children and elderly people. In addition to these two variables, the percentage of adults with no more than a Primary School education and the percentage with a Third Level qualification will also be used as indicators. Emigration is selective in nature, giving rise to a demographic structure which is skewed towards elderly people, who tend to have relatively low levels of educational attainments; average levels of educational participation tend to increase with each successive age cohort.

Turning to Social Class Disadvantage, the Irish Census of Population assigns individuals to class categories depending on both their occupation (higher or lower professional, non-manual, semi-skilled manual and unskilled manual classes) and their land-holdings (for farmers). The 'Semi-skilled Manual' category includes small farmers, and by combining the semi- and unskilled manual social classes, we obtain a powerful indicator of weak social class composition. The absence of affluent and wellconnected individuals from an area is also relevant to its social class profile - middleclass families provide additional resources for community self-organisation - and for this reason we have included measures of 'high social class' as well as of 'low social class'. The 'Higher Professional' social class includes farmers with 200 acres of land and more, and those with between 100 and 199 acres are allocated to the 'Lower Professional' class. We therefore combine the 'Higher Professional' and 'Lower Professional' social class categories in order to obtain a robust measure.

The definition of social class categories employed in the Irish Census of Population is problematic, however, as the category 'Other Non-manual' groups together 'whitecollar' employees who cannot be assigned to the 'professions'. The weakness of this 
classificatory scheme is further underlined by the fact that a significant proportion of the workforce cannot be classified at all. The percentage of people whose social class position is 'Unclassified' can reach very high levels, exceeding 40 per cent in the most deprived areas of Dublin, Waterford and Limerick. This clearly casts doubt on the adequacy of the remaining categories. As the 'Unclassified' category includes amongst others - people who have never been in paid employment, it is likely that the size of the semi- and unskilled manual categories understates the extent of disadvantage in deprived areas. In order to counteract this problem, we have removed all 'Unclassified' individuals from the denominator of our measure of the semi- and unskilled manual social classes.

The close relationship between class and education has encouraged social scientists to explore the ways in which class background conditions young people's experience of the school environment, thus reproducing the class structure over time. For many disadvantaged school students, the perceived likelihood of unemployment or lowskilled work feeds into disillusionment with the educational system. Conversely, low educational attainments can represent a major handicap within a 'credentialised' labour market in a state of rapid change, and these processes form part of a broader system of inequality that is highly resistant to change. Our indicators of Social Class Disadvantage include the percentage of adults with no more than a Primary School education and the percentage of adults with a Third Level qualification. These two variables have already been mentioned in relation to Demographic Decline, and we will use them as indicators of both this and Social Class Disadvantage. The final indicator of Social Class Disadvantage is the average number of persons per room, which reflects housing quality and overcrowding. 
'The Measurement of Social Disadvantage'

As far as Labour Market Deprivation is concerned, we will use the following indicators: the percentage of economically-active men who are unemployed, the percentage of economically-active women who are unemployed and the percentage of households containing children aged 15 years and under which are headed by a single parent. The inclusion of unemployment variables requires little justification, given the centrality of paid employment to individual and collective well-being in contemporary society. However, theoretical arguments may be required in order to broaden prevailing definitions of labour market deprivation beyond unemployment. We have included a measure of lone parenting because those in receipt of Lone Parents' Allowance are not classified as unemployed and because high rates of lone parenting and unemployment tend to coincide spatially, due to the criteria used to allocate social housing.

Preliminary modelling results, using Census of Population data for 1996, suggested two relationships that were not initially anticipated. Firstly, there is a significant relationship between Labour Market Deprivation and the size of the Semi- and Unskilled Manual social classes (an indicator of Social Class Disadvantage). This is because unskilled workers have a particularly weak labour market situation, which exposes them to a disproportionate risk of unemployment. Secondly, Demographic Decline is inversely related to the percentage of lone-parent households. In fact, areas with high rates of lone parenting often have moderate to high rates of demographic growth, and this variable may thus be used as an (inverse) indicator of demographic decline. These cross-loadings generalise to both 1991 and 2002 data, indicating their robustness. 
Table 1 lists the names and definitions of all indicator variables included in the model, as well as the dimensions of disadvantage with which they are associated. Two of the variables were estimated using proxies for 1991, due to changes in variable definitions, and one was interpolated for 1996 on the basis of the 1991 and 2002 values, as housing data are only collected every ten years in Ireland ${ }^{5}$. As the distribution of some of these variables is not perfectly normal, we have transformed certain indicators to improve their distributional properties (see Table 2).

Table 1 Variable Names, Areas Affected and Dimensions Insert here

Table 2 Variables, Transformations, Estimation and Scaling Insert here

Formatted: Space After: $0 \mathrm{pt}$

V Review of Existing Methodologies

The methodological challenge posed by the construction of a disadvantage index is to combine a set of indicator variables, lying along one or more dimensions, in order to produce a single measure. In the case of the current index, we have ten indicator variables and wish to obtain estimates for three dimensions. The most straightforward approach would involve adding together the values of each of the variables corresponding to a given dimension, perhaps following standardisation, and this technique has been widely applied within the field of deprivation modelling. However, 
it has been criticised on the grounds that it fails to take into account the pattern of covariances between indicator variables and domains_(Folwell, 1995; Hayduk, 1987: 212-216) As we have argued, disadvantage is a multi-dimensional concept, and all additive approaches tend to apply an implicit weighting according to the number of indicators or domains falling within each dimension.

The second approach to the weighting of indicator variables that one encounters relies on a specially-commissioned survey (Forrest and Gordon, 1995; Gordon, 1995). For example, Gordon (1995) uses an individual-level survey to derive weights for six Census proxies. The weights are calculated using a logistic regression equation in which the dependent variable is a dichotomous measure of individual deprivation constructed using a 'checklist' of deprivation items; an individual is classified as deprived if they are lacking three or more 'essential goods' (cf. Gordon and Townsend, 1990). This assumes that deprivation is a unidimensional concept, as survey-based approaches require a single, definitive measure of deprivation at the individual level, which in this case appears rather arbitrary. Arguably, no single individual-level variable can capture the different dimensions of social disadvantage. Above all, however, the survey-based approach may be criticised for deriving weights from an individual-level model and then applying them at the aggregate level.

The third approach to the weighting of indicator variables found in the literature relies on Principal Components Analysis (PCA) or other forms of Exploratory Factor Analysis (EFA), and these are undeniably the most commonly-used techniques in the construction of disadvantage indices (cf. Haase, 1998; McIntyre and Gilson, 2000; Salmond and Crampton, 2002). PCA and EFA techniques extract 'variance 
components' from a set of variables, which may be said to reflect the different dimensions of disadvantage. They are therefore consistent - at least in principle - with a dimensional analysis and a large number of variables can be included in the analysis without requiring specific theoretical justification. Examples of indices that use PCA include Carstairs and Morris (1990), Duncan and Aber (1997), Haase (1995, 1999), McIntyre et al. (2000), SAHRU (1997) and Salmond and Crampton (2002). Noble et al. use a different form of Factor Analysis, Maximum Likelihood Exploratory Factor Analysis (EFA), instead of PCA.

The main weakness of EFA and PCA, as far as the measurement of disadvantage is concerned, is that all of the variables included in the analysis are treated as being related to all of the components or factors. This can lead to ambiguities in interpretation, as the definition of the components or factors depends on the precise pattern of the loadings ${ }^{7}$. Further problems arise from the tendency for researchers to use the first component of an EFA or PCA as a unidimensional index of disadvantage. Although this component or factor may account for a large proportion of the overall variance, this practice can sideline important aspects of disadvantage.

The third problem with EFA and PCA is their sensitivity to the attributes of individual datasets. For example, because of the interpretational difficulties mentioned above, components and factors are often 'rotated'; different rotations give rise to different relationships between the indicators and the components/factors. The choice between 'oblique' and 'orthogonal' rotations determines whether the components/factors will be correlated or not, but even these are algebraically equivalent representations of the same mathematical solution. In short, EFA factor scores and PCA scores are not comparable 
over time and space and are therefore not suitable for monitoring spatially targeted public programmes.

A number of important methodological debates have taken place in recent years in relation to other aspects of the construction of disadvantage indices, including the standardisation, smoothing, transformation and estimation/extrapolation of values. However, as far as the weighting of indicator variables is concerned, the only approaches found in the literature are those described above: adding the standardised and/or transformed variables (with or without the use of ad hoc weights), using a separate regression model with sample data or applying factor analytic techniques.

To summarise, the main problems that must be overcome when combining indicator variables involve (a) controlling for dimensionality and measurement error; (b) producing a stable and interpretable set of dimensions and (c) avoiding arbitrary operational decisions that make it impossible to compare scores. A more powerful and general form of statistical analysis, known as Structural Equation Modelling, can provide acceptable solutions to all of these problems, enabling us to incorporate latent variables within longitudinal analyses (Bollen, 1989; Loehlin, 1992). The dimensions of disadvantage are conceptualised on theoretical grounds and indicator variables are constructed to measure these. There are statistical tests to assess whether the dimensions specified by the model are consistent with the data. Each dimension is linked with a subset of indicator variables, which simplifies interpretation, and the latent variables control for errors of measurement in the observed variables. Weights can be created for the indicator variables according to established statistical criteria, which can be used to estimate disadvantage scores for each individual area. Above all, factor score estimates 
are comparable from one period of time to another, and from one country to another, as long as the model has the same structure (Meredith, 1993).

\section{Model Specification and Assessment}

All of our statistical models will be estimated using Structural Equation Modelling (SEM) software9. In statistical terms, Structural Equation Models (of which Confirmatory Factor Analysis models represent a special case) place constraints on the joint distribution of the observed variables by omitting paths or correlations from the saturated model and by imposing 'equality constraints' on parameters (Bentler, 1995). Because SEM models draw on theoretical knowledge to specify these constraints, they are empirically testable,

Model estimation is accomplished by using a 'fitting function' which indicates how closely the covariance matrix implied by the model conforms to the observed data. In mathematical terms, one can express this in terms of the null hypothesis $\Sigma=\Sigma(\theta)$, where $\Sigma$ is the population covariance matrix of the observed variables, $\Sigma(\theta)$ is the covariance matrix implied by the model and $\theta$ is a vector containing the free parameters of the model. Bollen and Long (1993) summarise the motivation behind this approach: "If the model [is] specified correctly and the distributional assumptions for the data [are] satisfied, analysts [can] use a test statistic with an asymptotic chi-square distribution to test the null hypothesis that the specified model leads to an exact reproduction of the 
population covariance matrix of the observed variables. A significant test statistic would cast doubt on the model specification" (p. 2) ${ }^{10}$.

All of the analyses presented in this article will rely on the Maximum Likelihood fitting function $^{11}$ and will be evaluated using a range of statistics and indices. Given the magnitude of our sample (well over 3,000 cases), the chi-square statistic is likely to have 'excessive' statistical power. The formula for chi-square shows that this statistic is dependent, in part, upon the sample size, which means that small discrepancies between the model and the observed data are 'magnified' in the context of large samples: "with very large samples we run into the opposite embarrassment, in that we may obtain highly significant $\chi^{2}$ s and hence reject models in cases where the discrepancies between model and data, although presumably not due to chance, are not large enough to be of any practical concern" (Loehlin, 1992: 65; see also p. 71; Fan et al., 1999).

Because of the high power of the chi-square test when large samples are used, a range of descriptive indices of model fit have been proposed. These indices enable researchers to evaluate models which may be satisfactory despite the presence of substantively trivial discrepancies (which are nevertheless sufficient to lead to model rejection when using large samples). $\mathrm{Hu}$ and Bentler (1999) review a range of indices, and on the basis of their discussion, we have decided to evaluate the goodness-of-fit of the models presented in this article using a decision rule which combines the Comparative Fit Index (CFI) (if this index falls below .95 we reject) with the Standardised Root Mean Square Residual (SRMR) (which should be equal to or less than .08). In the current case, we will use the 1996 Census of Population data to refine the hypothesised structural model, re-tested this using data from both 1991 and 2002. 


\section{Model Assessment and Interpretation}

The path diagrams shown in Figures 1,2 and 3 provide a graphical representation of the theoretical assumptions underlying our model of social disadvantage as well as providing the results for three waves of Census data. One-headed arrows in path diagrams correspond to regression equations in the statistical model and the 'delta' variables to the left of the diagrams denote error variables which account for the variance in the indicators not explained by the latent variables in the model. Twoheaded arrows, by contrast, represent correlations between the variables concerned. The three diagrams provide the results of the disadvantage model when estimated separately | using data from the Census of Population for 1991, 1996 and 2002. The unstandardised parameter estimates are included in the path diagrams, and the coefficient of determination $\left(R^{2}\right)$ is reported for each dependent variable, together with the latent variances.

Figure 1 Results of the Disadvantage Model, 1991 Census Data $(\mathrm{N}=3403)^{*}$

Insert here

Figure 2 Results of the Disadvantage Model, 1996 Census Data $(\mathrm{N}=3403)^{*}$ Insert here 
'The Measurement of Social Disadvantage'

Figure 3 Results of the Disadvantage Model, 2002 Census Data

$(\mathrm{N}=3403)^{*}$

Insert here

Formatted: Space After: 0 pt

The models depicted in Figures 1, 2 and 3, which are Confirmatory Factor Analysis (CFA) models, have good fit to the data according to the alternative fit indices, and the combination of the CFI and SRMR fit indices meet the criteria specified earlier: the CFI for the 1991, 1996 and 2002 models is $0.95,0.97$ and 0.95 respectively, and the SRMR is $0.05,0.03,0.05$ (see the Appendix for additional information on fit). One modification was made to the original model in order to achieve acceptable fit: a correlation between the error terms associated with the age dependency ratio and population change was added. This implies that the observed correlation between these two variables cannot be accounted for completely by the latent variable that they share, namely Demographic Decline. There is thus an intimate relationship between (selective) emigration and the subsequent demographic profile of local areas, and this effect is in accord with our theoretical model. The fact that this relationship generalises to all three

Deleted: it waves of data reinforces the view that this is a necessary structural component of the model.

VIII Analysing the Changing Pattern of Disadvantage

Formatted: Space After: 0 pt

In this section we will estimate our final disadvantage model, in which we simultaneously draw on data from the 1991, 1996 and 2002 Censuses of Population, 
specifying correlations between the latent variables. This model is more complex than the preceding ones, as it incorporates a number of additional correlations and equality constraints. Firstly, the error variables associated with corresponding indicators are allowed to covary across all three time points, a standard practice when specifying longitudinal models. Secondly, all corresponding factor loadings are constrained to be equal across waves in order to ensure that the meaning of the latent variables remains constant. These constraints make the strong assumption that a single set of parameter estimates can provide an adequate representation of the pattern of relationships between the observed variables over this eleven-year period.

The combined model falls slightly below the Hu-Bentler decision rule based on the combination of the CFI and the SRMR (the CFI is .94, compared to a suggested cut-off value of .95 , although the SRMR is satisfactory at 0.07 ). The size of this shortfall is nevertheless negligible and it is possible to meet the threshold value by including a small number of 'nuisance' factors which have very little impact on the estimated coefficients in the model. We will therefore proceed to estimate the factor scores using the combined model in its current form, using GLS Factor Score Estimation within EQS 6.1.

Whilst inspection of each of the three individual dimensions of disadvantage can shed light on the determinants of disadvantage in specific areas, the calculation of overall disadvantage scores remains of primary importance. It is therefore important to show how these can be derived from the component dimensions. Here it is necessary to return to our earlier methodological discussion, as the combination of dimension scores raises once again the question of dimensionality and bias,
Formatted: Space After: $0 \mathrm{pt}$ 
'The Measurement of Social Disadvantage'

It may be argued that both Demographic Decline and Labour Market Deprivation reflect the effects of adverse labour market conditions, and that an equal weighting should be accorded to these two dimensions due to the roughly equal division of the Irish population between rural and urban areas. It is less clear how they should be weighted vis-à-vis Social Class Disadvantage, however, as one could argue that the social class composition of a local area is its most fundamental attribute. However, this could lead to areas with a relatively weak social class composition being classified as more disadvantaged than areas with very high unemployment or emigration rates. As the correlation between Demographic Decline and Labour Market Deprivation is near zero, we should be concerned primarily about balancing each of these dimensions against Social Class Disadvantage. In order to give due weight to current labour market conditions as well as social class composition, we will estimate overall disadvantage by applying unit weights ${ }^{12}$. 'Double-counting' is avoided because the structure of the model is symmetrical and the correlation between the demographic and labour market dimensions is very small. This decision does not generate bias, as we have controlled for the dimensional structure of the indicator variables and ensured that the resulting structure provides a balanced view of the phenomenon.

Returning to the analysis of change in small areas, it is now possible to show how programme evaluation can be carried out in a rigorous fashion ${ }^{13}$. In this context, it is worth noting that a considerable amount of work has been carried out in Britain in relation to the evaluation of area-based initiatives (NESS, 2005; CRESR, 2004). Despite their methodological sophistication, it is noteworthy that these evaluations do not draw on the Indices of Multiple Deprivation for 2000 and 2004, despite the fact that the
Deleted: could plausibly 
authors express their desire for a summary measure that could be compared over time (e.g. NESS, 2005: 65). Due to changes in the administrative data used in these indices and the way in which they are estimated, such comparisons are effectively impossible.

In order to illustrate the spatial distribution of disadvantage, in this section we will present a series of thematic maps. Due to space constraints, we will not provide maps for each of the three underlying dimensions, but will confine our attention to the index of overall relative affluence and disadvantage for 1991 and 2002, in Ireland as a whole and Dublin. Each of the maps uses a three-point scale with equal ranges, all scores being centred on their mean for each timepoint, yielding a comparable measure of relative disadvantage for each wave of census data. The scores range, in broad terms,

from -50 to +50 , higher values indicating greater disadvantage,

Figure $4 \quad$ Social Disadvantage in Ireland, 1991

Deleted: affluence

Insert here

Figure 5 Social Disadvantage in Ireland, 2002

Insert here

Figures 4 and 5 reveal the great resilience of the socio-spatial patterning of disadvantage

Formatted: Space After: 0 pt 
the social geography of the Republic of Ireland: the dark areas in the map indicate the most disadvantaged tracts, which are concentrated primarily in the North-West and in the urban areas, which are themselves sharply polarised. An affluent belt is discernible around all of the major urban centres, indicating the desirability of these areas and their relatively privileged residential status. Figures 4 and 5 also provide an insight into the ways in which Dublin has expanded over the last ten years, and the relatively affluent areas of population growth in the hinterland of the city are clearly evident. The extension of the commuter belt outwards from the city is also apparent, due to population growth in areas such as Glendalough, Blessington, Rathmore, Naas, Newcastle, Maynooth, Celbridge, Kilcock and Dunshaughlin.

The inserts for Dublin are equally striking, confirming the social polarisation of this city, which assumes the form of a marked North-South divide. These maps reveal the processes of repopulation and gentrification of the Inner City, with the result that the area within the two canals is now rather affluent. Large-scale private housing development in the City Centre, driven by the economic boom, has led to a significant influx of dual-earner couples and young families, a relatively income-rich and affluent population which has produced a significant change in social composition (Pratschke, 2004). The transformation of the Inner City is all the more dramatic given the overall stability of the spatial pattern of relative affluence and disadvantage in Ireland. Two important consequences flow from this: firstly, given the stability of relative disadvantage scores over time, it is arguably not necessary to update these scores at regular intervals, as we are unlikely to detect significant changes over a period of less than ten years. Secondly, where substantial changes are detected, following for example an intense period of economic growth and redevelopment as in the case of Dublin, it is 
1

2

3

4

5

6

7

8

9

clear that we need composite measures that can actually measure the magnitude of the changes observed. Indices that do not permit comparisons to be made over time or which base their analysis of change on rankings rather than the disadvantage scores themselves are therefore of limited value.

Formatted: Space After: $0 \mathrm{pt}$ X Concluding Remarks

In this paper, we have applied Confirmatory Factor Analysis techniques to Census of Population data from the Republic of Ireland to construct an estimate of social disadvantage at local level. We emphasised the importance of building operational hypotheses upon an understanding of the characteristics of communities and the areas they live in, rather than automatically referring to an individual-level model which may not be appropriate. Indeed, one of the consequences of using spatial data from the Census of Population to estimate social disadvantage is that definitions and theories relating to individuals and households are no longer sufficient. By focusing on the attributes of areas, however, it is possible to provide a superior picture of how spatiallydifferentiated outcomes emerge and are reproduced over time. 
'The Measurement of Social Disadvantage'

\section{Appendix}

Table 3 below summarises goodness of fit statistics and alternative fit indices for the 1991, 1996, 2002 and combined models.

Table 3 Goodness of Fit Statistics and alternative fit indices for 1991, 1996 and 2002 models as well as combined model$$
\text { (n) }
$$

Insert here 
Bibliography

Bentler P. (1995) EQS Structural Equations Program Manual. Multivariate Software, Inc., California.

Bollen K. and Long J. S. (Eds.) (1993) Testing Structural Equation Models. Sage, Newbury Park.

Bollen K. (1989) Structural Equations with Latent Variables. John Wiley, New York.

Carstairs V. and Morris R. (1990) Deprivation and Health in Scotland, Health Bulletin 48, $162-74$.

CRESR (2004) New Deal for Communities: The National Evaluation. NRU, London.

Cressie N. (1993) Statistics for Spatial Data. Wiley, New York.

Department of the Environment UK (1983) 1981 Deprivation Index. HMSO, London.

Department of the Environment UK (1994) 1991 Deprivation Index: A Review of Approaches and a Matrix of Results. HMSO, London.

Dorling D, Mitchell R, Shaw M, Orford S, Davey Smith G (2000) The health effects of poverty in London in 1896 and 1991, British Medical Journal 321, 1547-1551.

Duncan G. and Aber J. L. (1997) Neighbourhood models and measures, in J. BrooksGunn et al. (Eds) Neighbourhood Poverty: Context and Consequences for Children, Vol. 1, pp. 62-78. Russell Sage Foundation, New York.

Fan X., Thompson B. and Wang L. (1999) Effects of sample size, estimation methods, and model specification on structural equation modeling fit indices, Structural Equation Modeling, 6(1), 56-83.

Folwell K. (1995) Single measures of deprivation, Journal of Epidemiology and Community Health 49 (Supplement 2), S51-S56. 
'The Measurement of Social Disadvantage'

Forrest R. and Gordon D. (1995) People and places: social and economic distinctions in England, Vol. 2. School for Advanced Urban Studies, Bristol.

Furstenberg F. and Hughes M. (1997) The influence of neighbourhoods on children's development: A theoretical perspective and a research agenda, in J. Brooks-Gunn et al. (Eds.) Neighbourhood Poverty, Vol. 2, pp. 23-47. Russell Sage Foundation, New York. Gordon D. and Townsend P. (1990) Measuring the Poverty Line, Radical Statistics 47, $5-12$.

Gordon D. (1995) Census based deprivation indices: their weighting and validation, Journal of Epidemiology and Community Health 49 (Supplement 2), S39-S44.

Gregory I., Southall H. and Dorling D. (2000) A century of poverty in England and Wales, 1898-1998: A geographical analysis, in J. Bradshaw and R. Sainsbury (Eds), Getting the Measure of Poverty. The Early Legacy of Seebohm Rowntree, pp. 130-159. Policy Press, Bath.

Haase T. (1995) The Designation of Disadvantaged Areas in the Local Development Programme, Report to Area Development Management Ltd., Dublin.

Haase T. (1998) The Role of Data in Policies for Distressed Areas, in OECD, Integrating Distressed Urban Areas. Organisation for Economic Cooperation and Development (OECD), Paris.

Haase T. (1999) Affluence and Deprivation: A Spatial Analysis Based on the 1996 Census of Population. Report to Area Development Management, Dublin.

Hu L. and Bentler P. (1999) Cutoff Criteria for Fit Indexes in Covariance Structure Analysis: Conventional Criteria Versus New Alternatives, Structural Equation Modeling 6(1), 1-55.

Jarman B. (1984) Underprivileged Areas: Validation and Distribution of Scores, in British Medical Journal 289, 1587-92. 
Loehlin J. (1992) Latent Variable Models: An Introduction to Factor, Path and Structural Analysis. Erlbaum, Hillsdale.

Lupton R. and Power, A. (2004) What We Know About Neighbourhood Change: A Literature Review, Case Report 27, London School of Education, London.

McIntyre, D. and Gilson L. (2000) Redressing Dis-advantage: Promoting Vertical Equity within South Africa, Health Care Analysis 8, 235-258.

McLennan W. (1998) 1996 Census of population and housing: Socio-economic indexes for areas. Australian Bureau of Statistics, Canberra.

Meredith W. (1993) Measurement invariance, factor analysis and factorial invariance,

Psychometrika 58, 525-543.

NESS (2005) Changes in the Characteristics of Sure Start Local Programmes Areas in Rounds 1 to 4 between 2000/2001 and 2002/2003. HMSO, London.

Noble M., Penhale B., Smith G. and Wright G. (1999) Index of Deprivation 1999 Review: Measuring Multiple Deprivation at the Local Level. Working Paper, Department of Applied Social Studies and Social Research, Oxford.

Noble M., Smith G., Penhale B., Wright G., Dibben C., Owen T. and Lloyd M. (2000a) Measuring Multiple Deprivation at the Local Level: The Indices of Deprivation 2000. Department of the Environment, Transport and the Regions, London.

Noble M., Smith G.A.N., Wright G., Dibben C., Lloyd M. and Penhale B. (2000b) Welsh Index of Multiple Deprivation. National Assembly for Wales, Cardiff.

Noble M., Smith G.A.N., Wright G., Dibben C. and Lloyd M. (2001) Measures of Deprivation in Northern Ireland. Northern Ireland Statistics and Research Agency, Belfast. 
'The Measurement of Social Disadvantage'

Noble M., Wright G., Lloyd M., Dibben C., Smith G., Ratcliffe A., McLennan D., Sigala M. and Anttila C. (2003) Scottish Indices of Deprivation. Department of Social Policy and Social Work, Oxford.

Noble M., Barnes H., Smith G., McLennan D., Dibben C., Anttila C., Sigala M., Avenell D., Smith T. and Mokhtar C. (2005) Northern Ireland Multiple Deprivation Measure. Northern Ireland Statistics and Research Agency, Belfast.

Pratschke J. (2002) Mapping the Dynamics of Disadvantage in the Republic of Ireland. MA Dissertation in Social Science Data Analysis, Essex Summer School in Social Science Data Analysis and Collection, University of Essex, Colchester.

Pratschke J. (2004) The Dynamics of Social Disadvantage in Dublin, 1991-2002, in N. Boccella and A. Billi (Eds.) Développement, inégalités, pauvretés, pp. 331-376. Éditions Karthala, Paris.

Robson B., Bradford M. and Deas I. (1994a) Relative Deprivation in Northern Ireland. Centre for Urban Policy Studies, Manchester University, Manchester.

Robson B., Bradford M. and Tye R. (1994b) A matrix of deprivation in English authorities 1991, in Department of the Environment UK (1994) 1991 Deprivation Index: A Review of Approaches and a Matrix of Results. HMSO, London.

SAHRU (1997) A National Deprivation Index for Health and Health Services Research. Technical Report No. 2 (August), Small Area Health Research Unit, Trinity College, Dublin.

Social Exclusion Unit (SEU) (1998) Bringing Britain together: a national strategy for neighbourhood renewal. SEU, London.

Salmond C. and Crampton P. (2002) Heterogeneity of deprivation within very small areas, Journal of Epidemiology and Community Health 56, 669-670. 
1

2

4

5

6

7

8

9

10

11

12

13

14

15

16

17

18

19

20

21

22

23

24

25

26

27

28

29

30

31

32

33

34

35

36

37

38

39

40

41

42

43

44

45

46

47

48

49

50

51

52

53

54

55

56

57

58

59

60

Shaw M., Dorling D., Gordon D. and Smith, G. (2001) Putting time, person and place together: the temporal, social and spatial accumulation of health inequality, Critical Public Health 11(4), 289-304.

Taylor D. (1998) The natural life of policy indices: Geographical problem areas in the US and UK, Social Science and Medicine 47(6), 713-725.

Townsend P. (1979) Poverty in the United Kingdom: A Survey of Household Resources and Standards of Living. Penguin, Harmondsworth.

Townsend, P., Phillimore, P. and Beattie, A. (1988) Health and Deprivation: Inequality and the North. Croom Helm, London.

Wilson W. J. (1987) The Truly Disadvantaged: The Inner City, the Underclass, and Public Policy. University of Chicago Press, Chicago.

Wright E. O. (1985) Classes. Verso, London. 
'The Measurement of Social Disadvantage'

Table 1 Variable Names, Areas Affected and Dimensions

\begin{tabular}{|c|c|c|c|}
\hline Name & Dimensions & $\begin{array}{l}\text { Types of Areas } \\
\text { Affected }\end{array}$ & Description \\
\hline AGEDEP & Demographic Decline & Mainly rural & $\begin{array}{l}\text { Percentage of population aged } \\
\text { under } 15 \text { or over } 64 \text { years }\end{array}$ \\
\hline POPCHG & Demographic Decline & Mainly rural & $\begin{array}{l}\text { Percentage change in population } \\
\text { over previous five years }\end{array}$ \\
\hline $\mathrm{EDLOW}_{-}$ & $\begin{array}{l}\text { Demographic Decline }+ \\
\text { Social Class Disadvantage }\end{array}$ & $\begin{array}{l}\text { Especially } \\
\text { deprived rural }\end{array}$ & $\begin{array}{l}\text { Percentage of adult population with } \\
\text { a Primary School education only }\end{array}$ \\
\hline EDHIGH & $\begin{array}{l}\text { Demographic Decline }+ \\
\text { Social Class Disadvantage }\end{array}$ & All & $\begin{array}{l}\text { Percentage of adult population with a } \\
\text { Third Level education }\end{array}$ \\
\hline HLPROF & Social Class Disadvantage & All & $\begin{array}{l}\text { Percentage of persons in households headed } \\
\text { by 'Professionals' or 'Managerial and } \\
\text { Technical' employees, including farmers } \\
\text { with } 100 \text { acres or more }\end{array}$ \\
\hline PEROOM & Social Class Disadvantage & All & The mean number of persons per room \\
\hline LONPAR & Labour Market Deprivation & $\begin{array}{l}\text { Especially } \\
\text { deprived urban }\end{array}$ & $\begin{array}{l}\text { The percentage of households with children } \\
\text { aged under } 15 \text { years and headed by a single } \\
\text { parent }\end{array}$ \\
\hline LSKILL & $\begin{array}{l}\text { Social Class Disadvantage + } \\
\text { Labour Market Deprivation }\end{array}$ & Mainly urban & $\begin{array}{l}\text { The percentage of persons in households } \\
\text { headed by 'Semi-skilled Manual' and } \\
\text { 'Unskilled Manual' workers, including } \\
\text { farmers with less than } 30 \text { acres* }\end{array}$ \\
\hline UNEMPM & Labour Market Deprivation & Mainly urban & $\begin{array}{l}\text { The male unemployment rate according to } \\
\text { the Census of Population }\end{array}$ \\
\hline UNEMPF & Labour Market Deprivation & Mainly urban & $\begin{array}{l}\text { The female unemployment rate according to } \\
\text { the Census of Population }\end{array}$ \\
\hline
\end{tabular}

* We exclude all those people whose social class position is 'Unclassified' from the denominator of this percentage, as to include them would lead to artificially-reduced scores in disadvantaged urban areas. 
Table 2 Variables, Transformations, Estimation and Scaling

\begin{tabular}{|c|c|c|c|}
\hline Name & Transformations & $\begin{array}{l}\text { Estimation of } \\
\text { missing waves }\end{array}$ & $\begin{array}{l}\text { Scaling } \\
\text { Factor** }\end{array}$ \\
\hline POPCHG & $\begin{array}{l}\text { Values constrained to } \\
\text { the range }+/-25 \%\end{array}$ & None & 1 \\
\hline AGEDEP & None & None & 1 \\
\hline EDLOW_- & None & $\begin{array}{l}\text { Values for } 1991 \text { estimated by applying } \\
\text { regression weights (obtained using } 1996 \\
\text { Census data) to the } 1991 \text { percentage of } \\
\text { people who had left school by } 16 \text { years } \\
\text { of age and the percentage who remained } \\
\text { in school beyond } 19 \text { years of age }\end{array}$ & 1 \\
\hline EDHIGH & $\begin{array}{l}\text { Natural logarithm of } \\
\text { percentage of population } \\
\text { with a Third Level } \\
\text { education plus one }\end{array}$ & $\begin{array}{l}\text { Values for } 1991 \text { estimated by applying } \\
\text { regression weights (obtained using } 1996 \\
\text { Census data) to the } 1991 \text { percentage of } \\
\text { people who had left school by } 16 \text { years } \\
\text { of age and the percentage who remained } \\
\text { in school beyond } 19 \text { years of age }\end{array}$ & 10 \\
\hline HLPROF & None & None & 1 \\
\hline PEROOM & None & $\begin{array}{l}\text { Values for } 1996 \text { estimated by calculating } \\
\text { the arithmetic mean of the } 1991 \text { and } 2002 \\
\text { values and adding a random error } \\
\text { variable of mean } 0 \text { and standard } \\
\text { deviation } 0.02\end{array}$ & 100 \\
\hline LSKILL & None & None & 1 \\
\hline UNEMPM & $\begin{array}{l}\text { Natural logarithm of } \\
\text { male unemployment rate } \\
\text { plus one }\end{array}$ & None & 10 \\
\hline UNEMPF & $\begin{array}{l}\text { Natural logarithm of } \\
\text { female unemployment } \\
\text { rate plus one }\end{array}$ & None & 10 \\
\hline LONPAR & $\begin{array}{l}\text { Natural logarithm of } \\
\text { percentage of lone } \\
\text { parent families plus one }\end{array}$ & None & 10 \\
\hline
\end{tabular}

** An arbitrary scaling factor is used prior to statistical modelling with Structural Equation Modelling software in order to render the variances of the variables more homogeneous. 
'The Measurement of Social Disadvantage'

Figure 1 Results of the Disadvantage Model, 1991 Census Data $(\mathrm{N}=3403)^{*}$

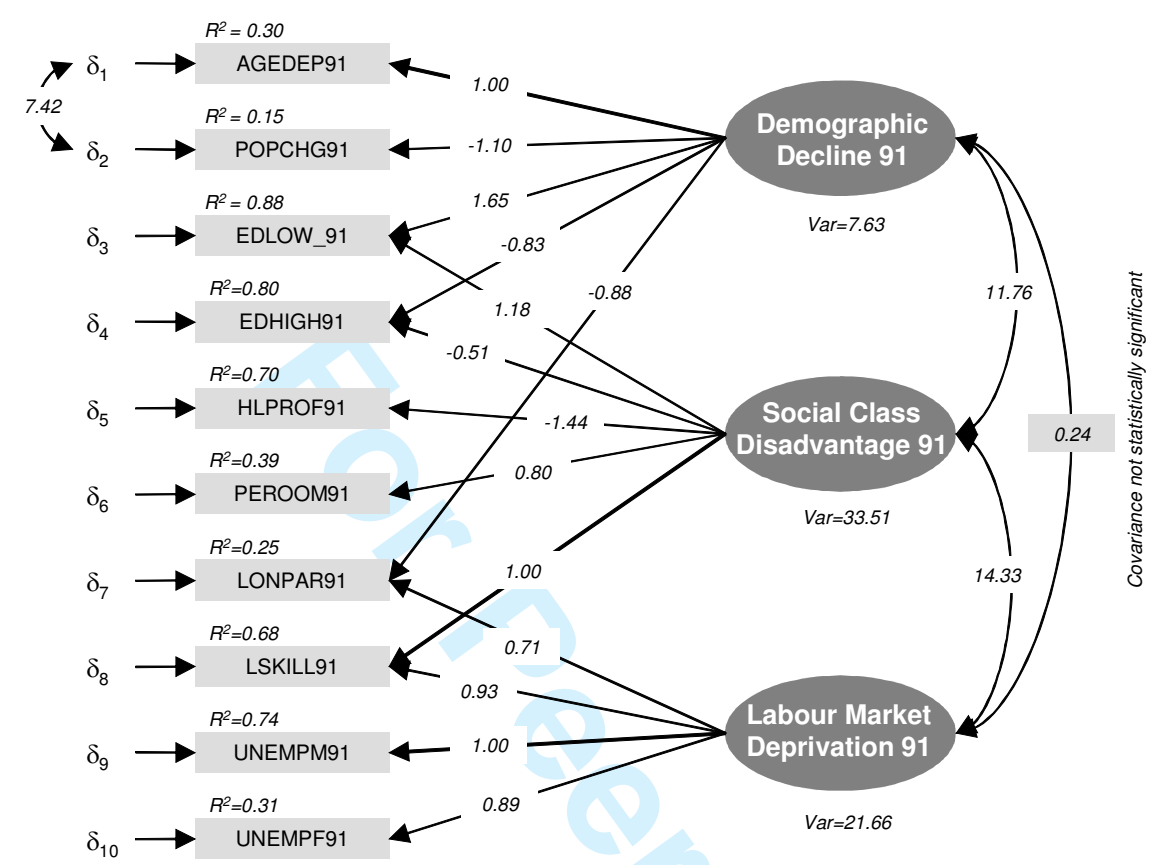

*All coefficients are unstandardised and all effects are statistically significant at the .05 level except where indicated. The unit factor loadings indicated in the graph (1.00) were imposed in order to identify the scale of the latent variables. 
Figure 2 Results of the Disadvantage Model, 1996 Census Data $(\mathrm{N}=3403)^{*}$

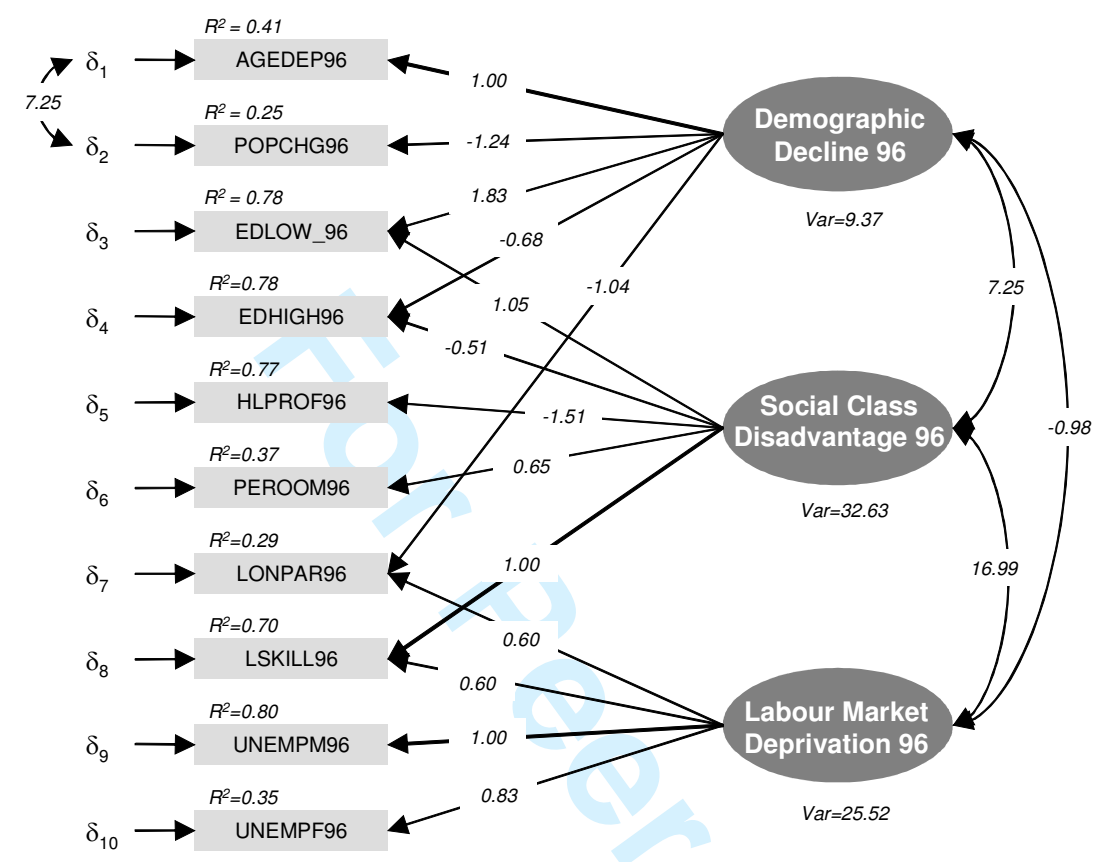

*All coefficients are unstandardised and all effects are statistically significant at the .05 level except where indicated. The unit factor loadings indicated in the graph (1.00) were imposed in order to identify the scale of the latent variables. 
'The Measurement of Social Disadvantage'

Figure 3 Results of the Disadvantage Model, 2002 Census Data $(\mathrm{N}=3403)^{*}$

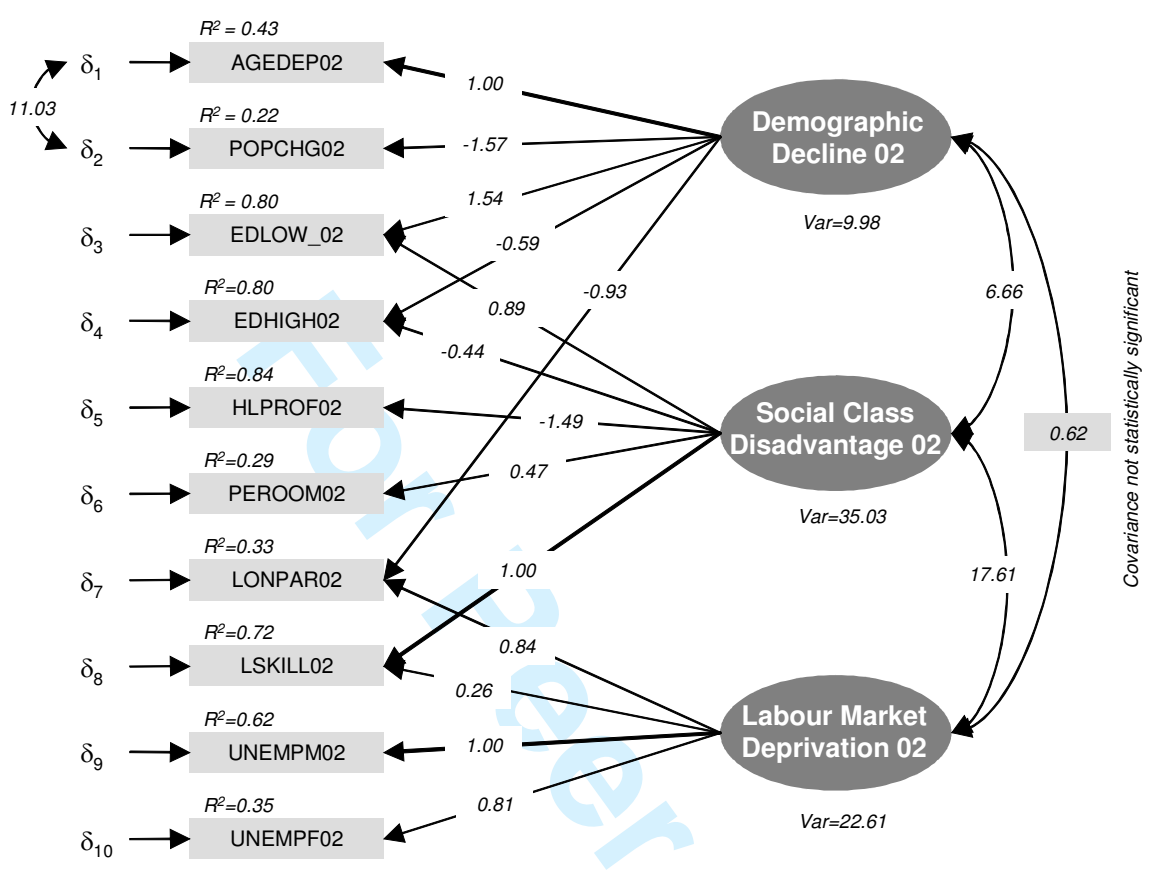

*All coefficients are unstandardised and all effects are statistically significant at the .05 level except where indicated. The unit factor loadings indicated in the graph (1.00) were imposed in order to identify the scale of the latent variables. 


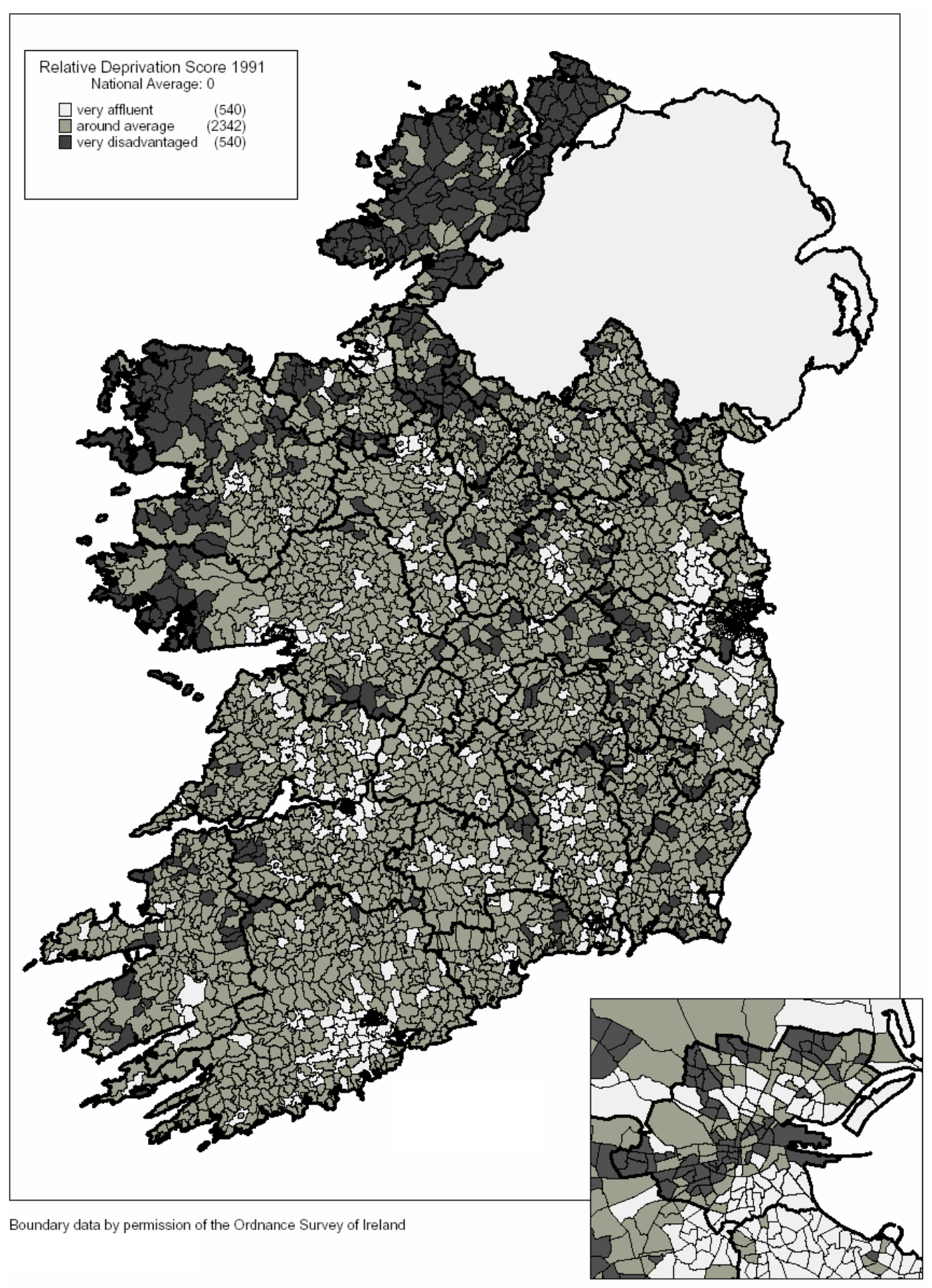




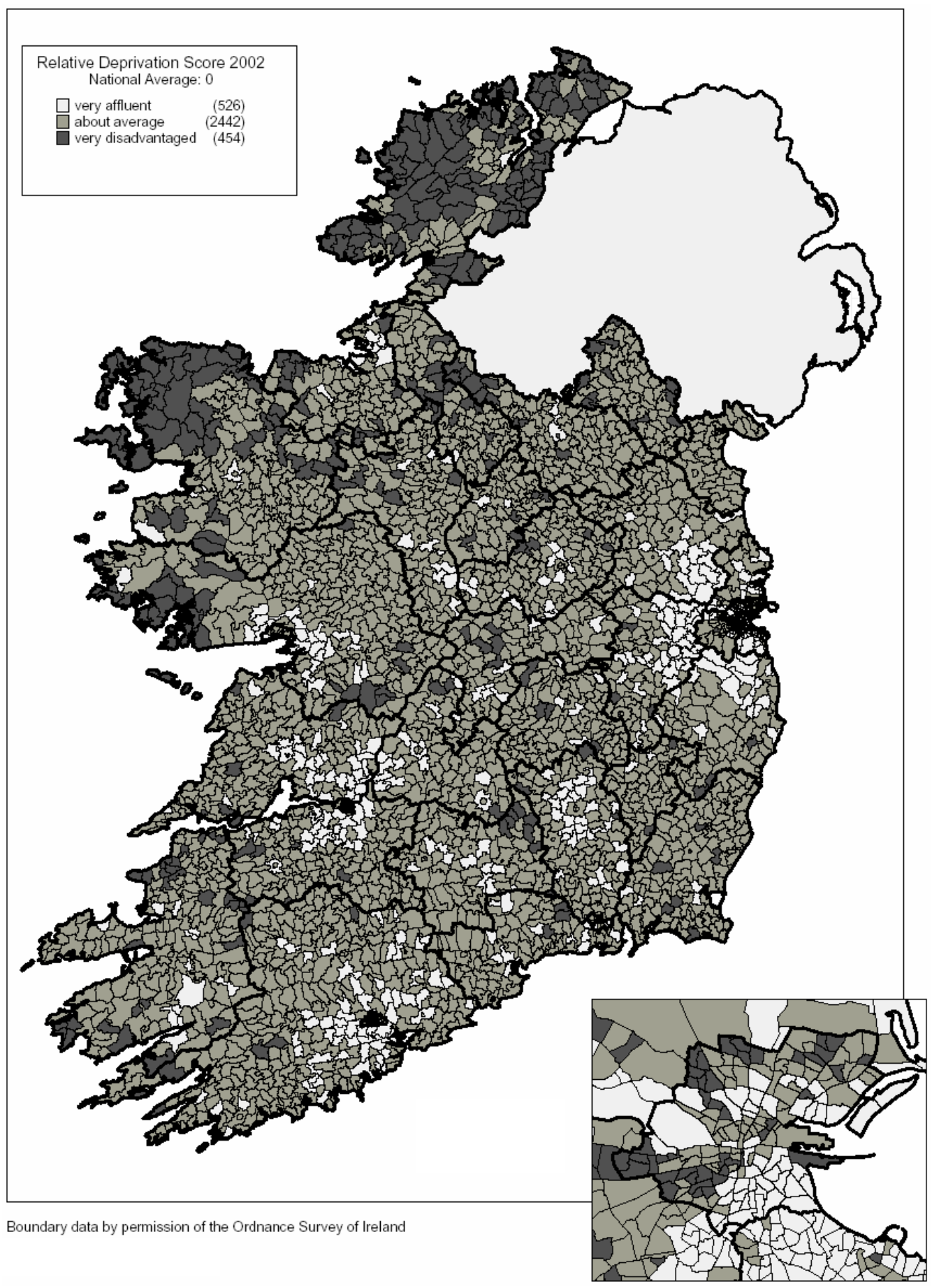

Page 1 
2

3

Table 3 Goodness of Fit Statistics and alternative fit indices for 1991, 1996 and 2002 models as well as combined model

\begin{tabular}{|c|c|c|c|c|}
\hline & 1991 & 1996 & 2002 & $\begin{array}{c}\text { Combined Model } \\
1991-2002\end{array}$ \\
\hline ML Chi-square: & 892.73 (27 df) & $546.92(27 \mathrm{df})$ & 881.38 (27 df) & 6297.13 (346 df) \\
\hline Probability: & 0.00000 & 0.00000 & 0.00000 & 0.00000 \\
\hline $\begin{array}{l}\text { S-B Scaled } \\
\text { Chi-square: }\end{array}$ & 673.40 & 403.78 & 662.36 & 4498.46 \\
\hline CFI: & 0.95 & 0.97 & 0.95 & 0.94 \\
\hline Bollen IFI: & 0.95 & 0.97 & 0.95 & 0.94 \\
\hline SRMR: & 0.05 & 0.03 & 0.05 & 0.07 \\
\hline RMSEA: & 0.10 & 0.08 & 0.10 & 0.07 \\
\hline
\end{tabular}

1 Well-known British indices include the Carstairs Index (Carstairs and Morris, 1990), the Jarman Index (Jarman, 1984), the Townsend Index (Townsend, Phillimore and Beattie, 1988), the DoE 1981 Index of Deprivation (DoE, 1983), the UK Index of Local Conditions (DoE, 1994), the English, Welsh, Scottish and Northern Irish Indices of Multiple Deprivation (Noble et al., 2000a, 2000b, 2001, 2003), the Northern Ireland Index of Relative Deprivation (Robson et al., 1994a) and the 'People and Places' Index (Forrest and Gordon, 1995). Indices for the Republic of Ireland have been proposed by Haase (1995) and SAHRU (1997). Duncan and Aber (1997) use Census of Population data from the US to construct an index of neighbourhood conditions. Outside Europe there are several other examples of deprivation indices, including South Africa (McIntyre et al., 2000), Australia (McLennan, 1998) and New Zealand (Salmond and Crampton, 2002).

2 It is interesting in this context that Geographical Access to Services, the most "rural" domain, is described as being negatively correlated with the other domains.

Deleted: revealing The Northern Ireland Multiple Deprivation Measure (Noble et al., 2005) seeks to address the issue of urban/rural bias within a similar set of domains. In relation to employment deprivation, for example, the authors conclude that "[t]here are no indicators which apply more specifically to urban areas than rural areas" (p. 12). This conclusion stands in marked contrast to the position set out in this article, as we will show in the following section. We believe that the correct measurement of 
deprivation in rural areas requires the development of theoretical models that address this issue directly.

3 Given that the average population of the census tracts in the Republic of Ireland is roughly 3,000, we feel that the presence of a Children's Home or Nursing Home is unlikely to exert an undue influence on this variable.

4 As the age profile directly affects rates of population change, it is important to consider whether it is possible to identify relatively affluent areas with elderly populations where population decline is directly attributable to the age profile rather than "demographic decline". If we take the example of relatively affluent "retirement villages", it will be clear that their elderly population profile does not necessarily lead to population decline, given the desirability of these areas: vacant properties will tend to be either re-let or sold.

5 The Census of Population 2001 was deferred until 2002 due to an outbreak of Footand-Mouth Disease.

7 It is not uncommon for inconsistencies and contradictions to be brushed aside: for example, Duncan and Aber (1997) never explain why, in their PCA, the percentage of adults out of work has a negligible loading on what they refer to as the 'Male Joblessness' component and why the percentage of adults with less than 12 years of schooling loads on 'High SES' but not 'Low SES'.

8 Confirmatory Factor Analysis initially developed as an extension of Exploratory Factor Analysis, and subsequently developed into 'Structural Equation Modelling'.

9 All model estimation and testing is carried out using Peter Bentler's programme EQS 6.1.

10 Another consideration that must be borne in mind when developing statistical models using spatial data is that the units of analysis are not independent, a fundamental assumption of linear models. Although this form of non-independence is likely to have an impact on standard errors and on global fit statistics (Cressie, 1993), statisticians have indicated that it is unlikely to bias parameter estimates themselves. This suggests that linear models may be used to generate disadvantage scores, even in the context of spatial data, but that one should use alternative measures of model fit and exercise considerable caution when carrying out hypothesis tests.

11 The ML fitting function yields an (asymptotic) chi-square, $\chi^{2}=(N-1) \mathrm{F}_{\min }$, where $\mathrm{F}_{\min }$ is the value of the discrepancy function at the point of best fit and $N$ is the sample size (assuming multivariate normality and a 'reasonably large' sample size; Loehlin, 1992: 59).

12 During the process of index construction, consideration was given to the question of whether the three dimensions should be completely standardised before calculating the overall scores. For example, it would be possible to divide each dimension by the mean standard deviation for that dimension for 1991, 1996 and 2002. However, as the three dimensions already have rather similar standard deviations, we decided that it was not necessary to apply any further transformations.

13 This can be achieved by specifying a longitudinal model with directed arrows (causal effects) between latent variables corresponding to successive timepoints. Each latent variable receives a causal input from the three dimensions of disadvantage at the previous wave. We then include a dummy variable identifying the areas targeted under the intervention, specifying this as an additional causal 
influence on the latent variables for the later wave, and allowing it to correlate with the latent variables for the previous wave. If we obtain a statistically significant coefficient for this effect, we can conclude that the intervention had an impact on the dimension concerned. This methodology will be explained in greater detail in a separate article due to space constraints. 